\title{
Nudging in education: from theory towards guidelines for successful implementation
}

\author{
Robert J. Weijers ${ }^{1}$ (D) B Björn B. de Koning ${ }^{1} \cdot$ Fred Paas $^{1,2}$ \\ Received: 6 February 2020 /Revised: 4 August 2020 / Accepted: 5 August 2020/ \\ Published online: 24 August 2020 \\ (C) The Author(s) 2020
}

\begin{abstract}
Nudging is one of the strategies from behavioral economics that aims to influence behavior by changing the environment. We propose that it could also be a valuable means to influence behavior in educational contexts. However, implementation of nudging in education is yet sparse. We describe the relevant issues to consider when applying nudging in education, arguing that a focus on the long-term effects and underlying processes of a nudge is necessary for successful implementation. Then, we aim to facilitate this implementation of nudging in education by making a distinction between nudges that is relevant for overcoming these issues. Based on the framework proposed by Hansen and Jespersen (European Journal of Risk Regulation, 4(1), 3-28, 2013), we distinguish between Type 1 and Type 2 nudges, and transparent and non-transparent nudges, resulting in four nudge categories. For each of these nudge categories, we determine its suitability for different educational goals. The resulting decision matrix can help researchers and practitioners when designing nudges for an educational context.
\end{abstract}

Keywords Nudging · Educational psychology $\cdot$ Learning behavior · Teaching strategies · Instructional support

Robert J. Weijers

weijers@essb.eur.nl

Björn B. de Koning

b.b.dekoning@essb.eur.nl

Fred Paas

paas@essb.eur.nl

1 Department of Psychology, Education, and Child Studies, Erasmus University Rotterdam, Burgemeester Oudlaan 50, 3062 PA Rotterdam, The Netherlands

2 School of Education/Early Start, University of Wollongong, Northfields Ave, Wollongong, NSW 2522, Australia 
In education, desired behavior is often difficult to achieve (Ruggeri 2019). Nudging theory (Thaler and Sunstein 2008) is a framework frequently used in behavioral science and behavioral economics, which asserts that subtle and indirect changes in the environment are effective means to change people's behavior and decision-making. In this article, we focus on successful implementation of nudging in education. To do so, we first investigate what nudge types utilize what cognitive processes and connect these underlying processes to different educational contexts. This results in a decision matrix that helps to determine what nudge type is best suited for a given educational context, or vice versa.

\section{Nudging}

A nudge is defined as "any aspect of the choice architecture that alters people's behavior in a predictable way without forbidding any options or significantly changing their economic incentives. To count as a mere nudge, the intervention must be easy and cheap to avoid." (Thaler and Sunstein 2008, p. 6). The book Nudge contains widely known examples, such as the inclusion of the image of a fly in the urinal to reduce spillage and the automatic optin instead of opt-out of a pension plan. Successful examples of these techniques include the addition of a descriptive social norm in tax letters (" 9 out of 10 people in Britain pay their tax on time") to increase tax payers' response by 5 percentage points (Cabinet Office Behavioural Insights Team 2012), using people's tendency to follow the crowd to promote compliance. Similarly, defaulting registration as an organ donor, so people are automatically a donor unless they opt out, leads to an increase in donors registered (Thaler and Sunstein 2008).

Nudges have been first introduced in the policy field to help people make improved decisions, and have thereafter widely been applied across various other domains associated with human behavior. Fields as diverse as health (e.g., improving stair usage by presenting health information in hospitals; Dorresteijn et al. 2013), safety (e.g., reducing speeded driving signs by providing real-time feedback; Sandberg et al. 2009), financial well-being (e.g., default enrolment in a pension plan; Thaler and Benartzi 2004), and climate (e.g., increasing towel reusage in hotels; Goldstein et al. 2008) have benefitted from the effectiveness of nudging in changing human behavior (Halpern 2015; Thaler and Sunstein 2008). The cost-effectiveness of nudge approaches has even led to the establishment of specialized nudge teams in both national and local government in several countries (Bhargava and Loewenstein 2015; Sunstein et al. 2018).

\section{Mechanisms of nudging}

Nudging is linked to dual process theory (Thaler and Sunstein 2008), according to which there are two cognitive systems for processing information. Dual process theory has a long history in cognitive psychology. Since its introduction by Wason and Evans (1974), many dual process theories have been developed, for example, in social psychology (e.g., Caplin and Martin 2016; Epstein 1998; Fiske and Neuberg 1990) and cognitive psychology (e.g., De Neys 2006; Geary 2008; Stanovich 1999; Stanovich and West 2000; for an overview of dual process theories, see Chaiken and Trope 1999; Evans 2008). In the past decades, the validity of a division between two processing systems has been debated and different labels have been 
introduced to refer to these dual systems (Melnikoff and Bargh 2018). In this article, we use the same conceptualization and labeling of dual process theory that was adopted by Thaler and Sunstein (2008) to explain nudging, namely System 1 and System 2, terms that were introduced by Stanovich (1999) and popularized by Kahneman (2011).

The terms "System 1" and "System 2" are used to describe two ways of processing information. System 1, also called "automatic," consists of uncontrolled, effortless, fast, associative, unconscious thinking. To facilitate this quick form of thinking, System 1 uses cognitive boundaries, biases, and rules of thumb to make decisions. Examples of characteristic behavior facilitated by System 1 are instinctual or habitual responses, like slowing down when approaching a dark tunnel, eating what is in front of you, or being startled when hearing a loud noise. System 2, also called "reflective," is controlled, effortful, slow, deductive, and selfaware, and represents a more deliberate way of thinking. Examples of characteristic behavior facilitated by System 2 are parking your car in a narrow space, comparing two TVs for best value, or filling out a tax form. As System 1 requires little effort compared to System 2, it often determines our behavior, instead of the careful deliberation by System 2. This can lead to behavior inconsistent with a person's long-term goals. For example, a person has the long-term goal to lose weight, but still engages in unhealthy behavior like snacking. The proposed lack of rationality of System 1 causes seemingly unimportant environmental cues to have a serious impact on behavior, while for the System 2, these cues should be irrelevant. For example, consumers buy wines consistent with the country of origin of background music in the store (North et al. 1999) and are more likely to choose a food item when it is placed in the center than when placed at the extremes of a display (Keller et al. 2015).

The central assumption of the theory underlying nudging is that, instead of trying to circumvent or fight the proposed lack of rationality of System 1, it should be accepted and used in a positive manner. Thaler and Sunstein (2008) advocate small changes (nudges) in the environment that make use of these shortcomings to alter people's behavior in a predictable manner, without limiting options or significantly changing economic incentives. These nudges make use of the proposed lack of rationality of System 1 to guide people towards improved decisions.

\section{Nudging in education: promises and challenges}

The popularization of nudging has not yet reached the field of education. A review on nudging by Szaszi et al. (2018) found that $42 \%$ of the identified studies were focused on promoting health, while only $4 \%$ were focused on nudges in the field of education. Additionally, a meta-analysis on the application of nudges by Hummel and Maedche (2019) showed that none of 96 analyzed nudging studies was conducted in the context of education. The present paper aims to close this gap. Specifically, we describe the promises and challenges that arise when applying nudging in an educational context, and what types of nudges are best suited for different educational settings in order to provide guidance towards the successful implementation of nudging in education.

\section{Promises}

Firstly, substantial similarity exists between education and the areas that nudging has already successfully been used in. Nudging aims to change behavior that is in line with a person's selfproclaimed goals (their System 2) but that they themselves fail to achieve due to automatic behavior (their System 1). Examples in an educational context would be realizing a deadline, 
paying attention in class, enrolling for college, or even arriving on time. Students would likely agree that they want to exhibit these behaviors, but experience problems to achieve these because of assumed interference from System 1; they lack willpower, postpone, or overestimate their own capabilities.

Secondly, the first steps have already been made to bring nudging to the educational field. These first steps have been documented in a thorough review by Damgaard and Nielsen (2018), who show that this is a promising direction for nudging. Nudges in education have proven successful in improving educationally relevant outcomes and behavior. The following examples demonstrate the diversity of the techniques and behavioral goals achieved using a nudging approach (for a complete overview, see Damgaard and Nielsen 2018). York et al. (2019) successfully increased the frequency of literary activities at home by sending the parents text reminders three times per week to engage in a literary activity. Clark et al. (2019) asked students to set task-specific goals for a course, which led the students to take more practice exams. A study by Lin-Siegler et al. (2016) managed to improve grades by providing the students with information about the struggles of well-known scientists. Student dropout was reduced substantially by a weekly one-sentence message about the student's performance from teacher to parents (Kraft and Rogers 2015). Successful applications for federal student aid were increased by 3.3 percentage points using repeated informational reminders about the application process (Page et al. 2020).

\section{Challenges}

While there is ample opportunity for, and already promising results of, bringing nudging to education, we also see challenges. Nudges that have been successful in different fields are not necessarily one-on-one transferrable to education. This is because the educational environment has its own characteristics. For example, educational goals are often long-term oriented, and attempts to change educational behavior are mostly aimed at long-term behavioral change (e.g., Dunlosky et al. 2013). However, at present, creating a long-term impact is one of the main challenges in nudging (Marchiori et al. 2017) and many nudging interventions fail to have long-lasting effects (Raymaekers et al. 2018). In other words, it is largely unclear what the effects of nudging are in the long-term. This is not surprising given that nudging research in general so far has mostly focused on immediate or short-term behavioral change (Marchiori et al. 2017; Raymaekers et al. 2018). Applied to education, it could be asked whether a nudge can facilitate long-term behavioral change in an educational setting? A related question is how long the effect remains when the nudge is removed. Perhaps a nudge can successfully function as an in-between explicit instruction and complete internalization of the desirable behavior, similar to scaffolding, a technique where instructional support is gradually decreased until students can independently perform a task (Wood et al. 1976). The answers of these questions are yet unknown and require more research. Answering these questions is beyond of the scope of this paper, but we aim to provide a framework that can help investigate these challenges.

Additionally, there is a responsibility to ensure that nudges applied within the educational context fit there. A nudge in education should not interfere with core educational principles like knowledge transfer or emancipation of citizens, nor should they have negative spillover effects in other important areas. Nudges should not interfere with or contradict these principles and should have an ultimately positive effect on students. This responsibility is enhanced because nudges in most other fields target adults, but a large part of the nudges in education target children. For nudging in 
education to be successful, negative direct or indirect effects on students or the educational process should be out of the question.

We identify a key aspect of overcoming these challenges to successful implementation of nudging in education: investigating the cognitive processes and subsequent behavior that a nudge affects. With this information, nudges can be introduced into the educational field in a more thoughtful way. We discuss the importance of the underlying processes of a nudge and, using this information, adapt an existing framework to identify which types of nudges are suitable for which educational context.

\section{The importance of underlying processes}

Nudges cannot directly influence an intended end goal, but use cognitive processes to create a change in behavior. This changed behavior can then help reach the intended end goal. In most fields, the primary indicator of success is reaching the end goal for which the nudge was created, not how the preceding underlying processes have changed. While an end goal can be a type of facilitated behavior (e.g., walking to the trash bin), often it goes a step beyond that, treating the nudged behavior as a stepping stone towards the end goal (e.g., a clean street). What this new behavior then consists of often receives less attention, as long as the end goal is sufficiently reached. This idea seems still rooted in the same traditional notions of rationality in policy making that Thaler and Sunstein (2008) argue against, where an intervention's expected utility is the criterion on which its success is measured. Still, this view is persistent. Indeed, Szaszi et al. (2018) report that across domains, only $42 \%$ of the reviewed papers focus on underlying processes of a nudge. For education specifically, Ruggeri (2019) claims that there is an overreliance on outcome measures when evaluating behavioral interventions.

Take the example of bright footsteps leading to a trash bin, a nudge that has been demonstrated in practice to decrease litter (e.g., Keep Britain Tidy 2013; Zero Waste Scotland 2015). In this case, the cognitive process through which this nudge worked is unclear and can take various forms. It can, for example, be sought in the footsteps grabbing attention, making the trash bin salient for the observer, but also in a subconscious descriptive norm, encouraging trash bin use by suggesting most others use this trash bin (Hansen, in Webster 2012). Additionally, what the nudged relevant behavior consists of is also unknown. There is more than one possible explanation for reduced littering in a certain street: people can use the trash bins more, but could also be littering elsewhere. As long as the results are in line with the end goal, these unknowns are often not investigated.

Especially in education, the cognitive processes and subsequent behavior in between a nudge and an end goal also deserve attention (Binder and Lades 2015) and could even be nudging goals themselves (Sunstein 2016). Currently, the end goal-focused nudging approach is continued when bringing nudging into education. More than half of the nudges in education described by Damgaard and Nielsen (2018) do not focus on improving behavior but on improving end goals that are not behaviors themselves, such as grades and course credits. Such an approach runs the risk of achieving these end goal through undesirable cognitive processes or unwanted behaviors. To establish a durable effect of nudges in education, we should not only focus on educational end goals, but also acknowledge that the cognitive processes and behaviors they display to achieve those end goals are well suited and educationally sound and responsible. We will demonstrate this using two examples. 


\section{The importance of underlying processes in education}

For our first example, consider a student, named Mark, who is underperforming in high school. To improve Mark's grades, the teacher may try to nudge him by showing his grades relative to those of his peers (as done by Azmat and Iriberri 2010). This simple informational nudge has proven successful in increasing grades by small margins (see Azmat and Iriberri 2010; Goulas and Megalokonomou 2015). In the traditional, end goal-focused view of nudging, the story ends here. This is a successful, cost-effective nudge to boost grades and should be implemented. However, from an educational perspective, it is important to look further to ensure that the cognitive process and nudged behavior of the student are positively or at least not negatively affected. It is possible that the nudge activated the student because he wanted to belong with his peer group; the cognitive process affected by the nudge would then be to activate a felt need to belong. This need to belong leads to the student collaborating more with his peers (affected behavior), improving his learning process. This improved learning process would result in a deeper understanding of the material and improved motivation, ultimately resulting in a higher grade (end goal). On the flip side, it is also possible that presenting this social norm caused stress because the student became afraid of failing the course (cognitive process affected by the nudge), and that the student tried to resolve this stress by using inefficient last-minute cramming or even cheating (affected behavior). Both paths lead to the student getting a better grade, but they are based on vastly different cognitive processes and behaviors, and greatly differ in their desirability for educators. Furthermore, the first path has possible positive long-term effects in the form of social bonds with peers or increased motivation for the course, while the second path has negative long-term consequences. Cramming as a learning strategy is less effective for knowledge retention, harming the long-term learning process, and a student successfully cheating on a test can lead to him forgoing learning altogether for the next one.

As demonstrated, it is important to not simply assume a nudge to work properly in education, but thus far, neither of these possible paths to behavior has been studied. Followup research on the aforementioned informational nudge has been focused on traits that moderate the effectiveness of the nudge, such as gender (Cabrera and Cid 2017), prior beliefs of relative performance (Azmat et al. 2019), ability, and sensitivity for feedback (Goulas and Megalokonomou 2015). No cognitive processes or changed behaviors caused by the intervention have been measured in studies using this intervention, so no conclusion can be drawn about whether the cognitive processes and behaviors created are desirable. When nudging in education, these cognitive processes and behaviors deserve attention, so nudges should not be implemented in education without scrutiny.

For our second example, consider a different nudge on the same student. In order to promote his grades, Mark is given the ability to determine his own deadlines for a course, as done in a study by Ariely and Wertenbroch (2002). However, at the end of the course, his grades were not higher, but lower than that of students who did not self-impose their deadlines. As this nudge failed to increase grades, in the end goal-focused view of nudging, it can be safely dismissed as ineffective. But again, this is not the whole story. It is well possible that, although Mark's grade went down, the nudge improved the learning process for the student by influencing cognitive processes or changing learning behavior. A possibility is that the student, due to experiencing more autonomy (cognitive process), decided to try and improve his planning (affected behavior). Although this behavior did not immediately lead to an increased grade, Mark still may have learned valuable lessons about his own planning skills from which 
he can benefit in the long term. This is a plausible explanation, as Ariely and Wertenbroch (2002) observed that students who set their own deadlines do so suboptimally, which can lead to lower grades but also a valuable learning experience. Indeed, a study by Levy and Ramim (2013) using a similar intervention found no effects on grades but observed less procrastination in students who self-imposed their own deadlines. This suggests that beneficial processes can be triggered by the nudge that are not immediately visible. More extensive research is needed to further substantiate this.

We have argued that a key aspect of nudging in education, namely the necessary focus on investigating cognitive processes and subsequent behavior, is required to successfully implement nudging in education. This focus allows educators to ensure that the right processes and behaviors are stimulated by a nudge, and more thoroughly investigate the positive or negative effects of a nudge, even if the directly observable end goal outcome has not changed.

\section{Towards successful implementation: different categories of nudges, different categories of processes}

Now that we have discussed the challenges to consider in applying nudges to education, we discuss different categories of nudges and their suitability for different educational contexts. In doing so, we rely on the framework provided by Hansen and Jespersen (2013). Although this framework is developed for responsible use of nudging in public policy, the distinctions between the category of a nudge and transparency of a nudge it makes are relevant for educational contexts as well. The two distinctions, namely between "Type 1" and "Type 2" nudges, and between transparent and non-transparent nudges result in four categories of nudges, as can be seen in Fig. 1. As both distinctions impact the suitability of a nudge, we can discuss the utility of the four resulting categories when implementing nudging in education. We will first describe these two distinctions and then elaborate on the four categories of nudges in relation to educational contexts.

\section{Type 1 and Type 2 nudges}

The first distinction made by Hansen and Jespersen (2013) is between "Type 1" and "Type 2" nudges, based on Thaler and Sunstein's (2008) distinction between System 1 and System 2. Type 1 nudges aim to influence behavior that is facilitated by automatic behavior, and do this without involving reflective thinking. A well-known example of a Type 1 nudge is reducing plate size to reduce calorie intake (Wansink and van Ittersum 2013). This nudge works in reducing food intake in cafeterias because consumers mindlessly conform to the reference of the plate size and put less food on their plate. A different example is automatic enrollment in exams, preventing students from simply forgetting to enroll. To the contrary, Type 2 nudges also engage the automatic system, but do this in order to trigger reflective thinking that subsequently shapes behavior. The fly-in-the-urinal nudge described earlier is an example of a Type 2 nudge. The fly is presumed to attract attention using the automatic system, and this attention triggers a reflective response of paying attention or even aiming to reduce spillage. A similar principle is used when hanging a poster in a classroom, reminding students to turn off their phones. In short, both types of nudges make use of automatic processes, but Type 1 nudges attempt to make use of behaviors that are not conscious and deliberate, while Type 2 nudges attempt to change deliberate actions and choices. 


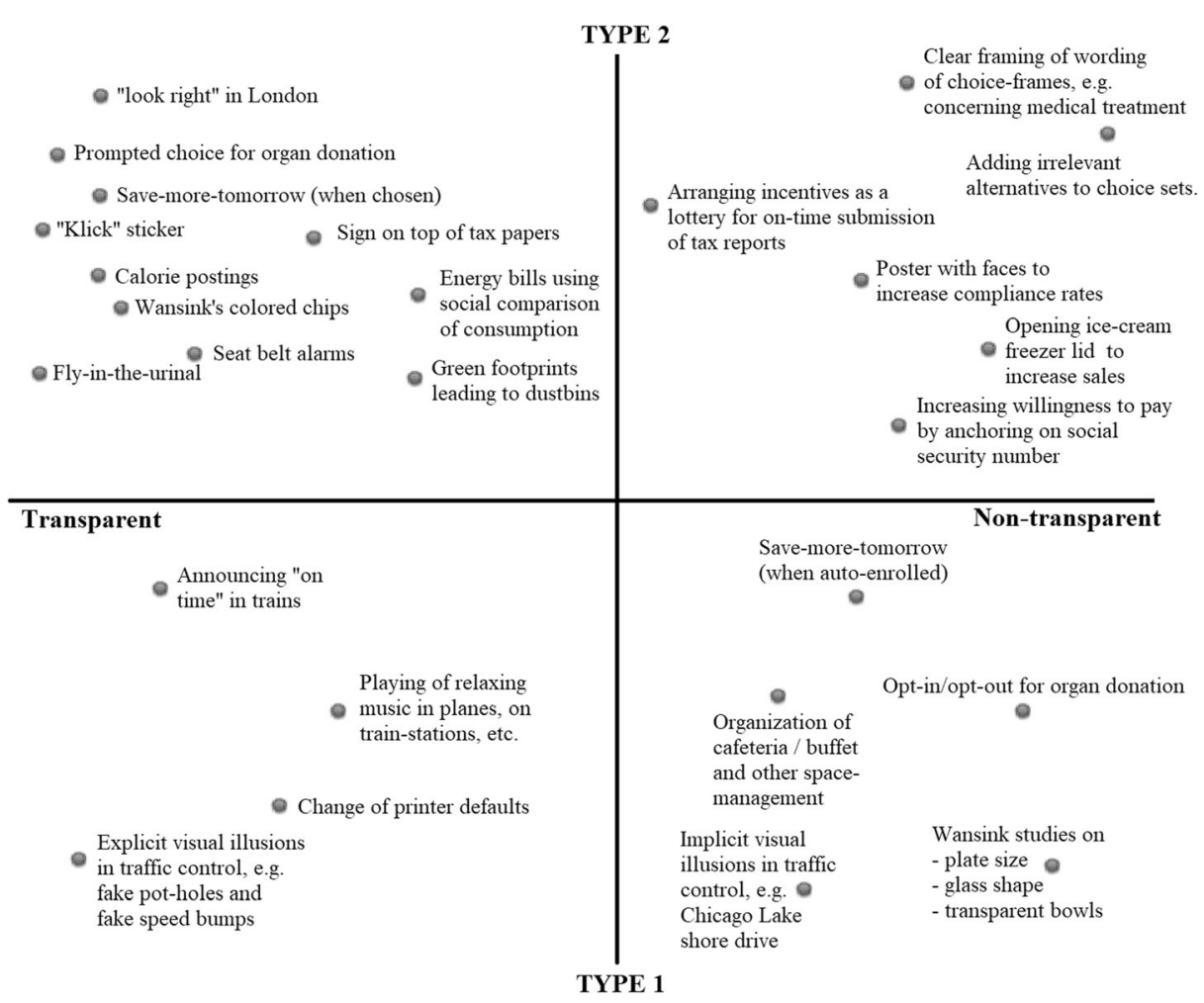

Fig. 1 Matrix depicting the four categories of nudges (Hansen and Jespersen 2013)

\section{Underlying processes of Type 1 and Type 2 nudges}

Type 1 and Type 2 nudges use different cognitive processes, and consequently, they differ as well in how suitable they are in achieving behavioral change in different situations. We argue that Type 1 nudges are better suited than Type 2 nudges in learning situations involving high cognitive load, but that Type 2 nudges are better suited than Type 1 nudges when achieving persistent behavioral change is important.

\section{Type 1: for situations with high cognitive load}

Type 1 nudges are more suitable than their Type 2 counterparts in situations where cognitive load is high. To explain this preference for Type 1 nudges in these situations, we rely on cognitive load theory, a theoretical framework concerned with the optimal design of instructions which makes use of the limitations of the human cognitive system (Sweller et al. 2019). When processing information, humans are heavily constrained by the capacity of their working memory. Cognitive demands on the capacity of the working memory are called cognitive load. Because optimal performance cannot occur when the total cognitive load exceeds the limit of the working memory (Paas et al. 2003), it is important to investigate ways to minimize unnecessary cognitive demands in the learning process.

Type 1 nudges are less cognitively demanding according to cognitive load theory because people do not engage in reflective processes when processing them. This makes Type 1 
nudges more suitable for situations characterized by an already high cognitive load. An example is highlighting an essential word of an exam question in red. The automatic attention towards the word does not substantially add to the already present cognitive load, but can nudge students to read carefully and provide a suitable answer.

In situations where cognitive load is not high, Type 1 nudges lose their advantage over Type 2 nudges, which have their own benefits, discussed below. A special case can be made for nudges that allow students to alleviate or regulate their own cognitive load, for which this distinction is less important. An example of a nudge stimulating the regulation of cognitive load would be a text box accompanying a video lecture, reminding a student to pause and rewind passages they do not quite grasp.

\section{Type 2: for persistent behavioral change}

Type 2 nudges are generally more successful in achieving long-term, persistent behavioral change. Both Type 1 and Type 2 nudges can create persistent behavioral change, using psychological mechanisms as memory of past utility (Ariely and Norton 2008) selfperception (Bem 1972), and repetition (Bandura 1997, in Hertwig and Grüne-Yanoff 2017). However, due to their reflective nature, Type 2 nudges benefit from additional processes that boost persistence, and use these paths more robustly (paths to persistence are described in detail by Frey and Rogers 2014), while still benefitting from the same processes that can make Type 1 nudges effective in this regard. This makes Type 2 nudges preferable over Type 1 nudges in attempts to facilitate persistent behavioral change. For example, teachers could ask their students to promise to be on time. This commitment nudge could initially support punctuality, but then, via the paths to persistence, become a new habit of the student, even if the initial promise has been forgotten.

However, not all situations call for persistent behavioral change. Some problems call for "one-and-done", situation-specific nudges, which are not concerned with persistence (Halpern 2015; Sanders et al. 2018). Examples include enrolling for college courses or focusing attention on a certain paragraph in an article. In these situations, Type 1 nudges are just as applicable.

The two areas in which the two categories have a benefit over the other are not mutually exclusive. In a situation where both persistence is desirable and high cognitive load is present, for example, when designing a nudge to prevent cheating during tests, the choice for Type 1 or Type 2 should be made by weighing the importance of achieving persistence against that of avoiding increased cognitive load.

\section{Transparency}

Along with the Type 1/Type 2 distinction, Hansen and Jespersen (2013) distinguish between whether a nudge is transparent or non-transparent. Hansen and Jespersen (2013) define a transparent nudge as "a nudge provided in such a way that the intention behind it, as well as the means by which behavioral change is pursued, could reasonably be expected to be transparent to the agent being nudged as a result of the intervention" (p. 17). According to the definition of Hansen and Jespersen (2013), examples of transparent nudges are the fly in the urinal (Thaler and Sunstein 2008) or signaling unhealthy content in products by using traffic light labeling, where healthy products get a green label, unhealthy products a red label, and products that are neither an orange label (Emrich et al. 2017), as well as asking students to 
set a grade goal (Clark et al. 2019). The nudge and its intended behavioral change are immediately apparent, even to laymen, making them transparent. On the other hand, nontransparent nudges include framing a question in a way that changes the response (Tversky and Kahneman 1981), exposing people to images of faces to make them more cooperative (Bateson et al. 2006), signing a car insurance form before filling it in, prompting honesty when providing details (Halpern 2015), or changing the classroom seating arrangement to reduce bullying (Van den Berg et al. 2012). In these cases, the fact that people are being nudged is unknown to the persons being nudged, and if the behavioral change attempt is recognized at all, the purpose of these nudges are not easily discerned by the layman.

\section{Effectiveness of transparency}

The extent to which non-transparent nudges are more effective than transparent nudges (and vice versa) is up for debate. Several sources claim that non-transparency boosts a nudge's effectiveness: Bovens (2009) claims that nudges "work best in the dark" (p. 13), and GrüneYanoff (2012) states that "[nudges] will be more effective if they are not transparent to the individuals subjected to them" (p. 637). However, Hansen and Jespersen (2013) call this conflict between transparency and nudges "overstate[d]" (p. 19), as according to them, this decreased effectiveness is only the case for Type 2 nudges that seek to promote behavioral changes that the nudged person does not agree with. This makes transparency an "ethical filter, making individuals immune when nudges are not aligned with the targeted individual's interest" (Hansen et al. 2016, p. 247). Some studies indeed indicate that transparency does not harm effectiveness. In a study by Bruns et al. (2018), participants were nudged using a default to donate their reward money to charity. For some participants, this default was accompanied with explicit information about its possible effect, explicit information about its goal, or both. All nudges did equally well and led to more money being raised for charity than in the control group. Similar results for default nudges were found in several experiments by Steffel et al. (2016). The evidence on the effectiveness of transparency, however, is far from conclusive (Marchiori et al. 2017). Furthermore, to our knowledge, no research has been done on the effect of nudge transparency in education. It is possible that transparency about behavioral goals motivates students to reach them (similar to goal setting; see Clark et al. 2019; Duckworth et al. 2013). Alternatively, persuasion attempts can cause resistance in students, leading to less of the desired behavior (Knowles and Linn 2004). More research is needed to investigate to what extent different levels of transparency influence the effectiveness of a nudge.

\section{Applying the framework to education}

As the given examples already demonstrated, the distinctions between Type 1 and Type 2, and between transparent and non-transparent are not mutually exclusive. These two distinctions allow nudges to be divided into four categories: transparent Type 1 nudges, non-transparent Type 1 nudges, transparent Type 2 nudges, and non-transparent Type 2 nudges. We now discuss for which educational situations these categories of nudges are best suited based on their characteristics. We provide examples from the educational field of how these different categories may look like when implemented and make suggestions based on successful nudges from different fields. 
Applying these four nudge categories in education leads to an adapted version of Hansen and Jespersen's (2013) nudge matrix. We filled this adapted matrix (see Fig. 2) with the educational nudges described below. As is evident, this version is not as full as the original. We expect that, with interest in nudging in education on the rise, this matrix can soon be filled with more experimentally tested nudges.

\section{Non-transparent Type 1 nudge}

A non-transparent Type 1 nudge is intended to support behavioral change without engaging the reflective system and of which the intent is unlikely to be recognized. An example of the non-transparent Type 1 nudge in education is the implementation of classical piano music in an elementary school lunchroom which reduced noise volume of the children by $12 \%$ and reduced the number of behavioral corrections by staff by $65 \%$ (Chalmers et al. 1999). Alternatively, Van den Berg et al. (2012) rearranged a classroom seating arrangement to place not-well-liked children closer to the children who disliked them, which resulted in less reported victimization in the class. A hypothetical example based on Barasz et al. (2017) is to utilize Gestalt psychology by presenting homework exercises in arbitrary sets to promote set completion.

Non-transparent Type 1 nudges can be effective solutions in situations where high cognitive load is a problem or for short-term context-specific behavior. A Type 1 nudge generally has difficulty creating sustainable behavioral change, instead relying on the situational cue to

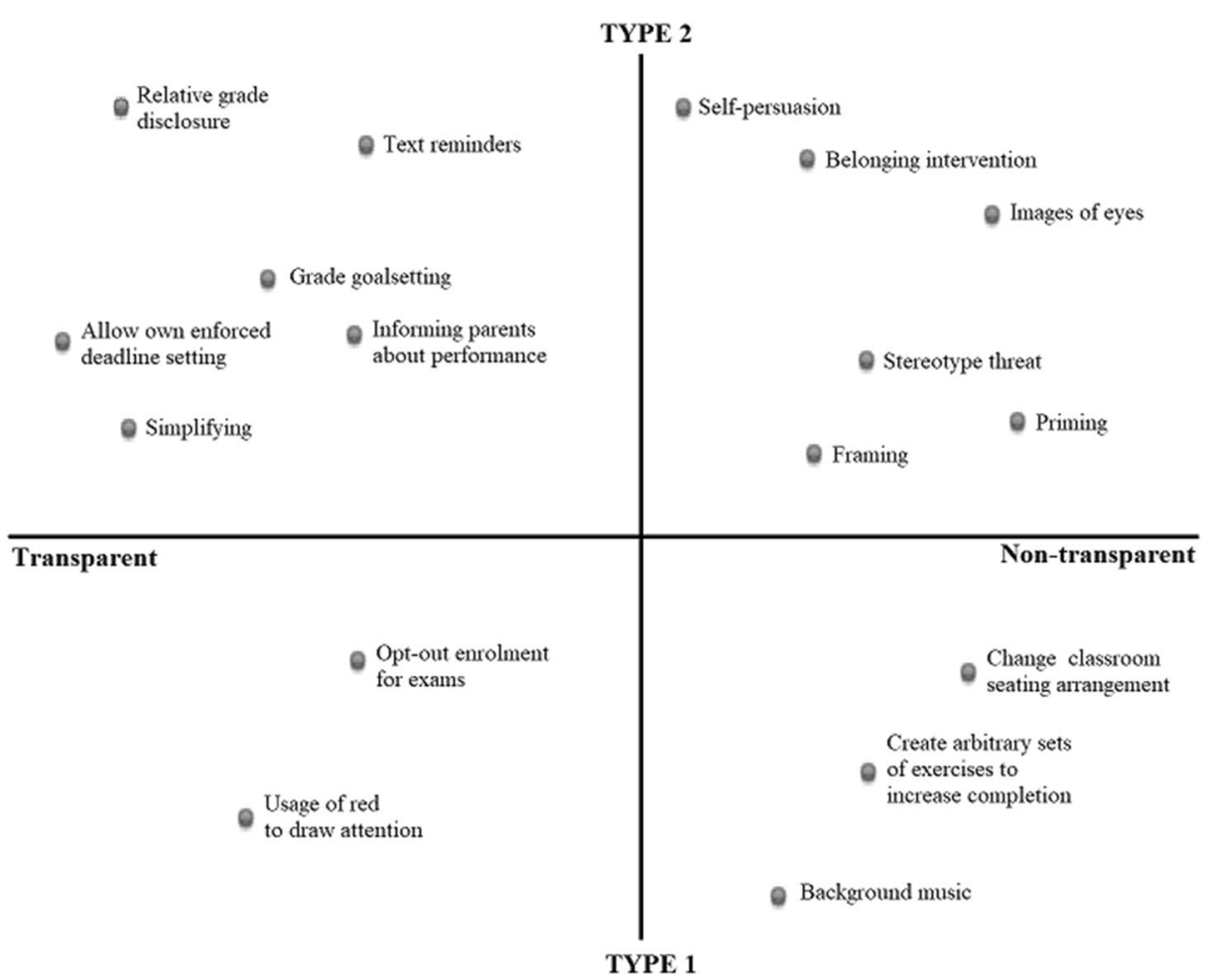

Fig. 2 Nudge matrix with examples of each of the four nudge categories within an educational context. Sources for each nudge can be found in Appendix 
make the behavior happen. Its non-transparent nature makes it important to investigate the cognitive processes that this nudge affects.

\section{Transparent Type 1 nudge}

A transparent Type 1 nudge causes behavioral change without engaging the reflective system but informs the targeted individuals of its purpose or at least works in such a manner that its purpose is clear. An example of a transparent Type 1 nudge in education is making enrollment for exams as opt-out instead of opt-in. The purpose of this default is reasonably evident for all students, making it transparent. This nudge does nothing to trigger reflective thinking, but works by engaging automatic thinking, as it relies on a student's inertia to provide them with the best outcome.

A transparent Type 1 nudge would be most suitable for cases in which cognitive workload should not be increased, for example, during exam weeks (as for the previously discussed default), a teacher's explanation or a test. An example would be the use of a salient color in an online course to suggest what to click next (Nielsen 2014) or the hypothetical example of highlighting the important parts of a learning text in red, as the color red instinctually draws attention (based on Hansen and Jespersen 2013).

Only a few examples of this category could be found in the current literature on nudging in education. This while it is best suited for changing behavior associated with contexts with high cognitive load. As these contexts, like tests, instruction, or complex assignments, are integral to education, we believe students could greatly benefit from more research towards the application of this category of nudge in educational contexts.

\section{Non-transparent Type 2 nudge}

On the other side of the matrix is the non-transparent Type 2 nudge. Nudges in this category use the reflective system, but do so in a way that its goal is not necessarily evident. An example of this nudge type is the belonging intervention for freshman students by Walton and Cohen (2011) that framed social adversity in school as shared and short lived. This encouraged students to attribute social adversity not to themselves but to the college adjustment process, both improving their self-reported well-being and their GPA in the long-term. Similar GPA increases have been achieved by an intervention aiming to create a growth mindset in students using self-persuasion (Paunesku et al. 2015). In a framing example, Benhassine et al. (2015) subjected parents to a frame where the financial support they received from the government for their school-aged child was labeled as intended to facilitate education. Their children were more likely to be enrolled in school and less likely to drop out - even more than for the parents whose financial support was contingent on their child's enrollment. A negative example of this nudge is the "stereotype threat," where girls performed worse in math tests when primed with their gender beforehand (Josephs et al. 2003). A hypothetical classroom example (suggested by Platform Integration and Society 2019) could be a priming nudge asking students to think of their relationship with a close family member to trigger feelings of safety before discussing controversial or sensitive topics with class, in order to reduce potential disruptions and increase constructive participation.

This nudge category is well suited for education, because of its potential to achieve sustainable behavioral goals. As the nudge is not apparent to its target audience, it is important 
that the processes and behaviors through which this is achieved are sound. In contexts of high expected cognitive load, this category of nudge should be avoided.

\section{Transparent Type 2 nudge}

The transparent Type 2 nudge achieves behavioral change by engaging the reflective system, while the goal of this nudge is clear. An example of a transparent Type 2 nudge in education is asking students to set specific goals for themselves (as in Duckworth et al. 2013; Clark et al. 2019). Students were, in the context of a course evaluation, asked to set task-specific goals. On average, these students completed more practice exams and achieved higher grades. A different example is simplifying and removing paperwork when applying for colleges, leading to more low-income students applying for college (Hoxby and Turner 2013).

This category of nudge is well suited for most educational contexts, as this nudge has both the benefits of being transparent and of eliciting reflective thinking (Type 2).

\section{Ethical considerations}

Before we move to the concluding remarks, we address the ethical aspects of these different nudge categories. Several studies that discuss the ethics of nudging make the distinction between Type 1 and Type 2 nudges. In a survey among Americans held by Jung and Mellers (2016), Type 2 nudges were preferred over Type 1 nudges, as they were perceived as more effective and less threatening to individual autonomy. Similarly, Sunstein et al. (2018) found that across countries, implementing a default (a Type 1 nudge) was less supported than informational nudges (a Type 2 nudge). Mongin and Cozic (2014) add the concern that defaults are dangerous in the long term, because it makes the act of not choosing a "dominant strategy." Binder and Lades (2015) expand on this idea, stating that Type 1 nudges "possibly reduce the individuals' ability to make critically reflected decisions" (p. 18), a sentiment echoed by Hausman and Welch (2010), who state that "no matter how well intentioned [...], one should be concerned about the risk that exploiting decision-making foibles will ultimately diminish people's autonomous decision-making capacities" (p. 135). However, it is important to note that both Type 1 and 2 nudges are supported by the majority of people across countries (Sunstein et al. 2018) and the permissibility of the nudge categories is largely tied to effectiveness: when asked to assume Type 1 nudges were more effective, many shifted their preference from Type 2 to Type 1 (Sunstein 2016).

A similar debate takes place concerning nudge transparency. Non-transparent nudges are often criticized for being manipulative and exploitative, decreasing the relative power of the nudged individual (Grüne-Yanoff 2012) and inviting abuse (Hansen et al. 2016). These are valid concerns, but it is important to note that in the context of education, even nudges classified by Hansen and Jespersen (2013) as transparent may prove to be not fully transparent given their target audience. In education, nudge targets are usually children, adolescents, or young adults, who generally are not yet fully capable to recognize attempts to influence behavior. Advertisements are overt attempts to influence behavior and would classify as transparent by the criteria set by Hansen and Jespersen (2013), but children often fail to recognize their purpose (Rozendaal et al. 2010). A failure to recognize persuasive intent makes every nudge non-transparent. This reinforces the need to check all transparent nudges whether they are indeed perceived as transparent, and check every nudge, not just the non-transparent ones, for their ethical acceptability. 


\section{Deciding what nudge category is appropriate}

With the different categories of nudging being better suited for different situations, we can imagine that it is difficult to decide what category to use in what situation. To provide guidance for nudge designers looking to bring nudging into education, Fig. 3 contains a decision matrix which can be consulted when deciding what kind of nudge to implement in the situation at hand, whether the previously designed nudge fits the setting or to explain the success or failure of an earlier implemented nudge in the educational field. Choosing for a transparent or nontransparent nudge is largely context-dependent, but we encourage nudge designers to prefer transparent nudges over non-transparent nudges.

\section{Conclusion}

In this article, we have argued that when implementing nudges into the educational field, it is important to focus on the cognitive processes and subsequent behaviors facilitated by a nudge, not just on its end goal. To facilitate the implementation of nudging in education, we have attempted to identify what nudges are best suitable to achieve different educational goals. We have identified four nudge categories: transparent Type 1 nudges, non-transparent Type 1 nudges, transparent Type 2 nudges, and non-transparent Type 2 nudges. These different categories serve different educational purposes. In general, Type 2 nudges are more effective for achieving long-term sustainable behavior. In situations where increasing cognitive load is undesirable, Type 1 nudges are better suited. In a situation where both achieving long-term sustainable behavior and avoiding increased cognitive load are desirable, a choice must be made based on the relative importance of both these goals. Additionally, it appears important to consider the transparency of a nudge. We have summarized these findings in a decision matrix and wherever possible have illustrated the four categories with relevant examples from the educational field.

Nudging in education is a new field of research, and not all categories are equally represented in the current literature. This gap of knowledge can provide direction for further research into nudging in education. Foremost, few examples of Type 1 nudges were found in the educational field. This while this category of nudges is best suited for situations in which cognitive load is high. In order to find nudges that can support behaviors during vital parts of learning, such as during instruction, training, or testing, this is an important area to investigate. We hope that nudge designers feel inspired to fill these gaps in the literature.

\begin{tabular}{|c|c|c|c|}
\cline { 3 - 4 } \multicolumn{2}{|c|}{} & \multicolumn{2}{c|}{ Is persistent behavioral change desirable? } \\
\cline { 2 - 4 } $\begin{array}{c}\text { Is the context a situation } \\
\text { with high expected } \\
\text { cognitive load? }\end{array}$ & YES & $\begin{array}{c}\text { Investigate context for } \\
\text { most appropriate } \\
\text { nudge type }\end{array}$ & Nype 1 nudge \\
\cline { 2 - 4 } & NO & Type 2 nudge & $\begin{array}{c}\text { Investigate context for } \\
\text { most appropriate } \\
\text { nudge type }\end{array}$ \\
\hline
\end{tabular}

Fig. 3 Decision matrix 
In short, nudges have potential to be valuable to anyone looking to facilitate behavioral change in education. When implementing nudging in education, attention from nudge designers is needed not only for the goal of the nudge, but also the processes and behaviors through which the nudge achieves this goal. The decision matrix offered can provide helpful for researchers, designers, and practitioners looking to investigate nudging in an educational setting. This distinction between nudge categories can also provide a good starting point for those who look for help with facilitating behavioral change in their educational environment.

Funding information This work was supported by the Dutch organization for scientific research (NWO) (grant number 40.5.18540.132).

\section{Compliance with ethical standards}

Conflict of interest The authors declare that they have no competing interests.

\section{Appendix. Sources and inspiration for the nudges in the education nudge matrix}

\section{Type 2-transparent}

Allow own enforced deadline setting-Ariely and Wertenbroch (2002)

Grade goalsetting - Duckworth et al. (2013); Clark et al. (2019)

Informing parents about performance-Kraft and Rogers (2015)

Relative grade disclosure - Czibor et al. (2014)

Simplifying-Hoxby and Turner (2013)

Text reminders-York et al. (2019)

\section{Type 2-non-transparent}

Belonging intervention-Walton and Cohen (2011)

Framing-Benhassine et al. (2015)

Images of eyes-Bateson et al. (2006)

Priming-Platform Integration and Society (2019)

Self-persuasion-Yeager et al. (2016)

Stereotype threat-Josephs et al. (2003)

\section{Type 1-transparent}

Opt-out enrolment for exams - common practice in Dutch universities

Usage of red to draw attention-Nielsen (2014)

\section{Type 1-non-transparent}

Background music - Chalmers et al. (1999)

Change classroom seating arrangement-Van den Berg et al. (2012)

Create arbitrary sets of exercise to increase completion-Barasz et al. (2017) 
Open Access This article is licensed under a Creative Commons Attribution 4.0 International License, which permits use, sharing, adaptation, distribution and reproduction in any medium or format, as long as you give appropriate credit to the original author(s) and the source, provide a link to the Creative Commons licence, and indicate if changes were made. The images or other third party material in this article are included in the article's Creative Commons licence, unless indicated otherwise in a credit line to the material. If material is not included in the article's Creative Commons licence and your intended use is not permitted by statutory regulation or exceeds the permitted use, you will need to obtain permission directly from the copyright holder. To view a copy of this licence, visit http://creativecommons.org/licenses/by/4.0/.

\section{References}

Ariely, D., \& Norton, M. I. (2008). How actions create-not just reveal-preferences. Trends in Cognitive Sciences, 12(1), 13-16. https://doi.org/10.1016/j.tics.2007.10.008.

Ariely, D., \& Wertenbroch, K. (2002). Procrastination, deadlines, and performance: self-control by precommitment. Psychological Science, 13(3), 219-224. https://doi.org/10.1111/1467-9280.00441.

Azmat, G., \& Iriberri, N. (2010). The importance of relative performance feedback information: evidence from a natural experiment using high school students. Journal of Public Economics, 94(7-8), 435-452. https://oi. org/10.1016/j.jpubeco.2010.04.001.

Azmat, G., Bagues, M., Cabrales, A., \& Iriberri, N. (2019). What you don’t know... can't hurt you? A field experiment on relative performance feedback in higher education. Management Science (8), 3449-3947. https://doi.org/10.1287/mnsc.2018.3131.

Bandura, A. (1997). Self-efficacy: the exercise of control. New York: Worth.

Barasz, K., John, L. K., Keenan, E. A., \& Norton, M. I. (2017). Pseudo-set framing. Journal of Experimental Psychology: General, 146(10), 1460-1477. https://doi.org/10.1037/xge0000337.

Bateson, M., Nettle, D., \& Roberts, G. (2006). Cues of being watched enhance cooperation in a real-world setting. Biology Letters, 2(3), 412-414. https://doi.org/10.1098/rsbl.2006.0509.

Bem, D. J. (1972). Self-perception theory. In Advances in experimental social psychology (Vol. 6, pp. 1-62). Academic Press.

Benhassine, N., Devoto, F., Duflo, E., Dupas, P., \& Pouliquen, V. (2015). Turning a shove into a nudge? A "labeled cash transfer" for education. American Economic Journal: Economic Policy, 7(3), 86-125. https://doi.org/10.1257/pol.20130225.

Bhargava, S., \& Loewenstein, G. (2015). Behavioral economics and public policy 102: beyond nudging. American Economic Review, 105(5), 396-401. https://doi.org/10.1257/aer.p20151049.

Binder, M., \& Lades, L. K. (2015). Autonomy-enhancing paternalism. Kyklos, 68(1), 3-27. https://doi. org/10.1111/kykl.12071.

Bovens, L. (2009). The ethics of nudge. In Preference change (pp. 207-219). Dordrecht: Springer.

Bruns, H., Kantorowicz-Reznichenko, E., Klement, K., Jonsson, M. L., \& Rahali, B. (2018). Can nudges be transparent and yet effective? Journal of Economic Psychology, 65, 41-59. https://doi.org/10.1016/j.joep.2018.02.002.

Cabinet Office Behavioural Insights Team. (2012). Applying behavioural insights to reduce fraud, error and debt. Retrieved from https://assets.publishing.service.gov.uk/government/uploads/system/uploads/attachment data/file/60539/BIT_FraudErrorDebt_accessible.pdf on 06-05-2020.

Cabrera, J. M., \& Cid, A. (2017). Gender differences to relative performance feedback: a field experiment in education. Facultad de Ciencias Empresariales y Economia. Universidad de Montevideo. Retrieved from http://www.um.edu.uy/docs/Gender_Differences_to_Relative_Performance_Feedback_A_Field_ Experiment in Education.pdf.

Caplin, A., \& Martin, D. (2016). The dual-process drift diffusion model: evidence from response times. Economic Inquiry, 54(2), 1274-1282. https://doi.org/10.1111/ecin.12294.

Chaiken, S., \& Trope, Y. (Eds.). (1999). Dual-process theories in social psychology. New York: Guilford Press.

Chalmers, L., Olson, M. R., \& Zurkowski, J. K. (1999). Music as a classroom tool. Intervention in School and Clinic, 35(1), 43-52. https://doi.org/10.1177/105345129903500108.

Clark, D., Gill, D., Prowse, V., \& Rush, M. (2019). Using goals to motivate college students: theory and evidence from field experiments. Review of Economics and Statistics, 1-45. https://doi.org/10.1162/rest_a_00864.

Czibor, E., Onderstal, S., Sloof, R., \& Van Praag, M. (2014). Does relative grading help male students? Evidence from a field experiment in the classroom. Tinbergen Institute Discussion Paper 14-116/V. https:/doi. org/10.2139/ssrn.2488550.

Damgaard, M. T., \& Nielsen, H. S. (2018). Nudging in education. Economics of Education Review, 64, 313-342. https://doi.org/10.1016/j.econedurev.2018.03.008. 
De Neys, W. (2006). Automatic - heuristic and executive - analytic processing during reasoning: chronometric and dual-task considerations. The Quarterly Journal of Experimental Psychology, 59(6), 1070-1100. https://doi.org/10.1080/02724980543000123.

Dorresteijn, J. A., van der Graaf, Y., Zheng, K., Spiering, W., \& Visseren, F. L. (2013). The daily 10 kcal expenditure deficit: a before-and-after study on low-cost interventions in the work environment. BMJ Open, 3(1), e002125. https://doi.org/10.1136/bmjopen-2012-002125.

Duckworth, A. L., Kirby, T. A., Gollwitzer, A., \& Oettingen, G. (2013). From fantasy to action: mental contrasting with implementation intentions (MCII) improves academic performance in children. Social Psychological and Personality Science, 4(6), 745-753. https://doi.org/10.1177/1948550613476307.

Dunlosky, J., Rawson, K. A., Marsh, E. J., Nathan, M. J., \& Willingham, D. T. (2013). Improving students' learning with effective learning techniques: promising directions from cognitive and educational psychology. Psychological Science in the Public Interest, 14(1), 4-58. https://doi.org/10.1177/1529100612453266.

Emrich, T. E., Qi, Y., Lou, W. Y., \& L'Abbe, M. R. (2017). Traffic-light labels could reduce population intakes of calories, total fat, saturated fat, and sodium. PLoS One, 12(2), e0171188. https://doi.org/10.1371/journal. pone. 0171188 .

Epstein, S. (1998). Cognitive-experiential self-theory: a dual process personality theory with implications for diagnosis and psychotherapy. In R. F. Bornstein \& J. M. Masling (Eds.), Emperical perspectives on the psychoanalytic unconscious (Vol. 7, pp. 99-140). Washington, DC: Am. Psychol. Assoc..

Evans, J. S. B. (2008). Dual-processing accounts of reasoning, judgment, and social cognition. Annual Review of Psychology, 59(1), 255-278. https://doi.org/10.1146/annurev.psych.59.103006.093629.

Fiske, S. T., \& Neuberg, S. L. (1990). A continuum of impression formation, from category-based to individuating processes: influences of information and motivation on attention and interpretation. In M. P. Zanna (Ed.), Advances in experimental social psychology (Vol. 23, pp. 1-74). San Diego: Academic Press.

Frey, E., \& Rogers, T. (2014). Persistence: how treatment effects persist after interventions stop. Policy Insights From the Behavioral and Brain Sciences, 1(1), 172-179. https://doi.org/10.1177/2372732214550405.

Geary, D. (2008). An evolutionarily informed education science. Educational Psychologist, 43(4), 179-195. https://doi.org/10.1080/00461520802392133.

Goldstein, N. J., Cialdini, R. B., \& Griskevicius, V. (2008). A room with a viewpoint: using social norms to motivate environmental conservation in hotels. Journal of Consumer Research, 35(3), 472-482. https://doi. org/10.1086/586910.

Goulas, S., \& Megalokonomou, R. (2015). Knowing who you are: the effect of feedback information on short and long term outcomes. Working paper.

Grüne-Yanoff, T. (2012). Old wine in new casks: libertarian paternalism still violates liberal principles. Social Choice and Welfare, 38(4), 635-645. https://doi.org/10.1007/s00355-011-0636-0.

Halpern, D. (2015). Inside the nudge unit: how small changes can make a big difference. London: Penguin Random House.

Hansen, P. G., \& Jespersen, A. M. (2013). Nudge and the manipulation of choice: a framework for the responsible use of the nudge approach to behaviour change in public policy. European Journal of Risk Regulation, 4(1), 3-28. https://doi.org/10.1017/S1867299X00002762.

Hansen, P. G., Skov, L. R., \& Skov, K. L. (2016). Making healthy choices easier: regulation versus nudging. Annual Review of Public Health, 37(1), 237-251. https://doi.org/10.1146/annurev-publhealth-032315-021537.

Hausman, D. M., \& Welch, B. (2010). Debate: to nudge or not to nudge. Journal of Political Philosophy, 18(1), 123-136. https://doi.org/10.1111/j.1467-9760.2009.00351.x.

Hertwig, R., \& Grüne-Yanoff, T. (2017). Nudging and boosting: steering or empowering good decisions. Perspectives on Psychological Science, 12(6), 973-986. https://doi.org/10.1177/1745691617702496.

Hoxby, C., \& Turner, S. (2013). Expanding college opportunities for high-achieving, low income students. Stanford Institute for Economic Policy Research Discussion Paper (12-014). Retrieved from https://www8.gsb.columbia. edu/programs/sites/programs/files/finance/Applied\%20Microeconomics/Caroline\%20Hoxby.pdf.

Hummel, D., \& Maedche, A. (2019). How effective is nudging? A quantitative review on the effect sizes and limits of empirical nudging studies. Journal of Behavioral and Experimental Economics, 80, 47-58. https://doi.org/10.1016/j.socec.2019.03.005.

Josephs, R. A., Newman, M. L., Brown, R. P., \& Beer, J. M. (2003). Status, testosterone, and human intellectual performance: stereotype threat as status concern. Psychological Science, 14(2), 158-163. https://doi. org/10.1111/1467-9280.t01-1-01435.

Jung, J. Y., \& Mellers, B. A. (2016). American attitudes toward nudges. Judgment and Decision making, 11(1), $62-74$.

Kahneman, D. (2011). Thinking, fast and slow. London: Penguin.

Keep Britain Tidy. (2013). Green Footprints Report. Retrieved from https://www.keepbritaintidy. org/sites/default/files/resources/KBT_CFSI_Green_Footprints_Report_2015.pdf on 06-02-2019. 
Keller, C., Markert, F., \& Bucher, T. (2015). Nudging product choices: the effect of position change on snack bar choice. Food Quality and Preference, 41, 41-43. https://doi.org/10.1016/j.foodqual.2014.11.005.

Knowles, E. S., \& Linn, J. A. (2004). Resistance and persuasion. New York: Taylor and Francis Group.

Kraft, M. A., \& Rogers, T. (2015). The underutilized potential of teacher-to-parent communication: evidence from a field experiment. Economics of Education Review, 47, 49-63. https://doi.org/10.1016/j. econedurev.2015.04.001.

Levy, Y., \& Ramim, M. M. (2013). An experimental study of habit and time incentive in online-exam procrastination. In Proceedings of the chais conference on instructional technologies research (pp. 53-61).

Lin-Siegler, X., Ahn, J. N., Chen, J., Fang, F. F. A., \& Luna-Lucero, M. (2016). Even Einstein struggled: effects of learning about great scientists' struggles on high school students' motivation to learn science. Journal of Educational Psychology, 108(3), 314-328. https://doi.org/10.1037/edu0000092.

Marchiori, D. R., Adriaanse, M. A., \& De Ridder, D. T. (2017). Unresolved questions in nudging research: putting the psychology back in nudging. Social and Personality Psychology Compass, 11(1), e12297. https://doi.org/10.1111/spc3.12297.

Melnikoff, D. E., \& Bargh, J. A. (2018). The mythical number two. Trends in Cognitive Sciences, 22(4), 280293. https://doi.org/10.1016/j.tics.2018.02.001.

Mongin, P., \& Cozic, M. (2014). Rethinking nudges. HEC Paris Research Paper No. ECO/SCD-2014-1067.

Nielsen, H. L. (2014). Curating and nudging in virtual CLIL environments. The EuroCALL Review, 22(1), 40-46.

North, A. C., Hargreaves, D. J., \& McKendrick, J. (1999). The influence of in-store music on wine selections. Journal of Applied Psychology, 84(2), 271-276. https://doi.org/10.1037/0021-9010.84.2.271.

Page, L. C., Castleman, B. L., \& Meyer, K. (2020). Customized nudging to improve FAFSA completion and income verification. Educational Evaluation and Policy Analysis, 42(1), 3-21. https://doi.org/10.3102 /0162373719876916.

Paas, F., Renkl, A., \& Sweller, J. (2003). Cognitive load theory and instructional design: Recent developments. Educational psychologist, 38(1), 1-4. https://doi.org/10.1207/S15326985EP3801_1.

Paunesku, D., Walton, G. M., Romero, C., Smith, E. N., Yeager, D. S., \& Dweck, C. S. (2015). Mind-set interventions are a scalable treatment for academic underachievement. Psychological Science, 26(6), 784 793. https://doi.org/10.1177/0956797615571017.

Platform Integration and Society. (2019). Primen in de praktijk? [Priming in practice?] Utrecht: Kennisplatform Integratie \& Samenleving.

Raymaekers, P., Fobé, E., \& Brans, M. (2018) Assessing the long-term effects of behavioural policy initiatives. Paper presented at the NIG Behavioural Administration Panel, 2 November 2018, The Hague.

Rozendaal, E., Buijzen, M., \& Valkenburg, P. (2010). Comparing children's and adults' cognitive advertising competences in the Netherlands. Journal of Children and Media, 4(1), 77-89. https://doi.org/10.1080 $/ 17482790903407333$.

Ruggeri, K. (Ed.). (2019). Behavioral insights for public policy: concepts and cases. New York and London: Routledge.

Sandberg, W., Schoenecker, T., Sebastian, K., \& Soler, D. (2009). Long-term effectiveness of dynamic speed monitoring displays (DSMD) for speed management at speed limit transitions. Retrieved from https://pdfs. semanticscholar.org/2d7a/0d4cbe207110fdcab75f6f705c0fafc973b6.pdf on 16-06-2020.

Sanders, M., Snijders, V., \& Hallsworth, M. (2018). Behavioural science and policy: where are we now and where are we going? Behavioural Public Policy, 2(2), 144-167.

Stanovich, K. E. (1999). Who is rational?: studies of individual differences in reasoning. New York: Psychology Press.

Stanovich, K. E., \& West, R. F. (2000). Individual differences in reasoning: implications for the rationality debate? Behavioral and Brain Sciences, 23(5), 645-665.

Steffel, M., Williams, E. F., \& Pogacar, R. (2016). Ethically deployed defaults: transparency and consumer protection through disclosure and preference articulation. Journal of Marketing Research, 53(5), 865-880. https://doi.org/10.1509/jmr.14.0421.

Sunstein, C. R. (2016). People prefer system 2 nudges (kind of). Duke LJ, 66, 121-168.

Sunstein, C. R., Reisch, L. A., \& Rauber, J. (2018). A worldwide consensus on nudging? Not quite, but almost. Regulation \& Governance, 12(1), 3-22. https://doi.org/10.1111/rego.12161.

Sweller, J., van Merriënboer, J. J., \& Paas, F. (2019). Cognitive architecture and instructional design: 20 years later. Educational Psychology Review, 1-32. https://doi.org/10.1007/s10648-019-09465-5.

Szaszi, B., Palinkas, A., Palfi, B., Szollosi, A., \& Aczel, B. (2018). A systematic scoping review of the choice architecture movement: toward understanding when and why nudges work. Journal of Behavioral Decision Making, 31(3), 355-366. https://doi.org/10.1002/bdm.2035.

Thaler, R. H., \& Benartzi, S. (2004). Save more tomorrow ${ }^{\mathrm{TM}}$ : using behavioral economics to increase employee saving. Journal of Political Economy, 112(1), 164-187. https://doi.org/10.1086/380085.

Thaler, R. H., \& Sunstein, C. R. (2008). Nudge: improving decisions about health, wealth, and happiness. London: Penguin. 
Tversky, A., \& Kahneman, D. (1981). The framing of decisions and the psychology of choice. Science, 211(4481), 453-458. https://doi.org/10.1126/science.7455683.

Van den Berg, Y. H., Segers, E., \& Cillessen, A. H. (2012). Changing peer perceptions and victimization through classroom arrangements: a field experiment. Journal of Abnormal Child Psychology, 40(3), 403-412. https://doi.org/10.1007/s10802-011-9567-6.

Walton, G. M., \& Cohen, G. L. (2011). A brief social-belonging intervention improves academic and health outcomes of minority students. Science, 331(6023), 1447-1451. https://doi.org/10.1126/science.1198364.

Wansink, B., \& Van Ittersum, K. (2013). Portion size me: plate-size induced consumption norms and win-win solutions for reducing food intake and waste. Journal of Experimental Psychology: Applied, 19(4), 320-332. https://doi.org/10.1037/a0035053.

Wason, P. C., \& Evans, J. S. B. (1974). Dual processes in reasoning? Cognition, 3(2), 141-154. https://oi. org/10.1016/0010-0277(74)90017-1.

Webster, G. (2012) Is a 'nudge' in the right direction all we need to be greener? Retrieved from https://edition. cnn.com/2012/02/08/tech/innovation/green-nudge-environment-persuasion/index.html.

Wood, D., Bruner, J. S., \& Ross, G. (1976). The role of tutoring in problem solving. Journal of Child Psychology and Psychiatry, 17(2), 89-100. https://doi.org/10.1111/j.1469-7610.1976.tb00381.x.

Yeager, D. S., Romero, C., Paunesku, D., Hulleman, C. S., Schneider, B., Hinojosa, C., Lee, H. Y., O'Brien, J., Flint, K., Roberts, A., Trott, J., Greene, D., Walton, G. M., \& Dweck, C. S. (2016). Using design thinking to improve psychological interventions: the case of the growth mindset during the transition to high school. Journal of Educational Psychology, 108(3), 374-391. https://doi.org/10.1037/edu0000098.

York, B. N., Loeb, S., \& Doss, C. (2019). One step at a time, the effects of an early literacy text-messaging program for parents of preschoolers. Journal of Human Resources, 54(3), 537-566. https://doi.org/10.1037 ledu0000098.

Zero Waste Scotland. (2015). Nudge study, implementation toolkit: promoting the use of street litter bins. Retrieved from http://www.zerowastescotland.org.uk/sites/default/files/ZWS\%20Litter\%20Nudge\%20 Study.pdf on 06-02-2019.

Publisher's note Springer Nature remains neutral with regard to jurisdictional claims in published maps and institutional affiliations.

Robert Weijers. Department of Psychology, Education, and Child Studies, Erasmus University Rotterdam, Burgemeester Oudlaan 50, 3062 PA, Rotterdam, The Netherlands. E-mail: weijers@essb.eur.nl

\section{Current themes of research:}

I am working on the implementation of nudging in education, specifically using nudging to promote selfregulated learning behavior in students.

Most relevant publications in the field of Psychology of Education:

None as of yet.

Dr. Björn de Koning. Department of Psychology, Education, and Child Studies, Erasmus University Rotterdam, Burgemeester Oudlaan 50, 3062 PA, Rotterdam, The Netherlands. E-mail: b.b.dekoning@essb.eur.nl

\section{Current themes of research:}

Optimizing learning from dynamic visualizations. Design of multimedia learning materials. Teaching and supporting the use of cognitive strategies. 
Cammeraat, S., Rop, G., \& De Koning, B. B. (2020). The influence of spatial distance and signaling on the splitattention effect. Computers in Human Behavior, 105, 106203.

De Koning, B. B., Wassenburg, S. I., Ganushchak, L., Krijnen, E., \& van Steensel, R. (in press). Inferencing questions embedded in a children's book help children make more inferences. First Language.

Wong, J., Khalil, M., Baars, M., De Koning, B. B., \& Paas, F. (2019). Exploring sequences of learner activities in relation to self-regulated learning in a massive open online course. Computers and Education, 140, 103595

De Koning, B. B., Marcus, N., Brucker, B., \& Ayres, P. (2019). Does observing hand actions in animations and static graphics differentially affect learning of hand-manipulative tasks? Computers and Education, 141, 103636.

Pouw, W. T. J. L., Rop, G., De Koning, B. B., \& Paas, F. (2019). The cognitive basis for the split-attention effect. Journal of Experimental Psychology: General, 148, 2058-2075.

De Koning, B. B., Hoogerheide, V., \& Boucheix, J-M. (2018). Developments and trends in learning with instructional video. Computers in Human Behavior, 89, 395-398.

Prof. dr. Fred Paas. Department of Psychology, Education, and Child Studies, Erasmus University Rotterdam, Burgemeester Oudlaan 50, 3062 PA, Rotterdam, The Netherlands. School of Education/Early Start, University of Wollongong, Northfields Ave, Wollongong NSW 2522, Australia. E-mail: paas@essb.eur.nl

\section{Current themes of research:}

Managing cognitive load in the learning of complex cognitive tasks. Using cognitive load theory to design instruction. The role of physical activity in the learning of cognitive tasks.

Most relevant publications in the field of Psychology of Education:

Castro-Alonso, J. C., Wong, A., Adesope, O. O., Ayres, P., \& Paas, F. (2019). Gender imbalance in instructional dynamic versus static visualizations: a meta-analysis. Educational Psychology Review, 31, 361-388.

Hoogerheide, V., Renkl, A., Fiorella, L., Paas, F., \& Van Gog, T. (2019). Enhancing example-based learning: teaching on video increases arousal and improves retention and transfer test performance. Journal of Educational Psychology, 111, 45-56.

Sepp, S., Howard, S., Tindall-Ford, S., Agostinho, S. \& Paas, F. (2019). Cognitive load theory and human movement: towards an integrated model of working memory. Educational Psychology Review, 31, $293-318$.

Sweller, J., Van Merriënboer, J. J. G., \& Paas, F. (2019). Cognitive architecture and instructional design: 20 years later. Educational Psychology Review, 31, 261-292.

Baars, M., Leopold, C., \& Paas, F. (2018). Self-explaining steps in problem-solving tasks to improve selfregulation in secondary education. Journal of Educational Psychology, 110, 578-595.

Chen, O., Castro-Alonso, J. C., Paas, F., \& Sweller, J. (2018). Extending cognitive load theory to incorporate working memory resource depletion: evidence from the spacing effect. Educational Psychology Review, 30, 483-501. 